\title{
Discordant effect of body mass index on bone mineral density and speed of sound \\ Miriam Steinschneider ${ }^{1}$, Philippe Hagag ${ }^{2,3}$, Micha J Rapoport ${ }^{1,3}$ and Mordechai Weiss*2,3
}

\author{
Address: ${ }^{1}$ Department of Medicine, Assaf Harofeh" Medical Center, Israel, ${ }^{2}$ Endocrine Institute, "Assaf Harofeh" Medical Center, Israel and ${ }^{3}$ Sackler \\ Faculty of Medicine, Tel Aviv University, Israel \\ Email: Miriam Steinschneider - msteinsneider@asaf.health.gov.il; Philippe Hagag - phagag@asaf.health.gov.il; \\ Micha J Rapoport - mrapoport@asaf.health.gov.il; Mordechai Weiss* - mweiss@asaf.health.gov.il \\ * Corresponding author
}

This article is available from: http://www.biomedcentral.com/147I-2474/4/15

(C) 2003 Steinschneider et al; licensee BioMed Central Ltd. This is an Open Access article: verbatim copying and redistribution of this article are permitted in all media for any purpose, provided this notice is preserved along with the article's original URL.

\begin{abstract}
Background: Increased BMI may affect the determination of bone mineral density (BMD) by dual X-ray absorptiometry (DXA) and speed of sound (SOS) measured across bones. Preliminary data suggest that axial SOS is less affected by soft tissue. The purpose of this study is to evaluate the effect of body mass index (BMI) on BMD and SOS measured along bones.

Methods: We compared axial BMD determined by DXA with SOS along the phalanx, radius and tibia in 22 overweight $\left(B M I>27 \mathrm{~kg} / \mathrm{m}^{2}\right)$, and II lean $\left(B M I=2 I \mathrm{~kg} / \mathrm{m}^{2}\right)$ postmenopausal women. Serum bone specific alkaline phosphatase and urinary deoxypyridinoline excretion determined bone turnover.

Results: Mean femoral neck - but not lumbar spine BMD was higher in the overweight - as compared with the lean group $(0.70 \pm 0.82,-0.99 \pm 0.52, P<0.0000 \mathrm{I})$. Femoral neck BMD in the overweight - but not in the lean group highly correlated with $B M I(R=0.68 . P<0.000 I)$. Mean SOS at all measurement sites was similar in both groups and did not correlate with BMI. Bone turnover was similar in the two study groups.

Conclusions: The high BMI of postmenopausal women may result in spuriously high BMD. SOS measured along bones may be a more appropriate means for evaluating bones of overweight women.
\end{abstract}

\section{Background}

Shortly after the introduction $[1,2]$ of dual X-ray absorptiometry (DXA) for measuring bone mineral density (BMD) it became apparent that BMD positively correlates with body mass index (BMI) in post- [3], and to a lesser degree in premenopausal women $[3,4]$. Voluntary weight loss results in bone loss in both young $[5,6]$ and elderly females $[7,8]$. Prospective studies indicate that early postmenopausal women with lower BMI-lose more bone as compared with those with higher BMI tertiles $[9,10]$. As thinness is related to both osteoporosis [11] and increased fracture risk [12], low BMI was included in the risk assessment tools for evaluation of osteoporosis $[13,14]$ and osteoporotic fracture risk [15].

The high BMD of overweight was attributed to a permissive effect of weight on the skeleton [16], suppression of circulating, increased aromatization of adrenal androgens 
by the adipose tissue [10], and vitamin D deficiency causing secondary hyperparathyroidism [17].

Accumulating data casts some doubt on the association of high BMI and BMD [18-20]. Evaluating cadaver bones indicates a significant contribution of soft tissue to the apparent BMD [21-23]. Wrapping lard around the body affects BMD to different extent by various densitometers and software versions $[23,24]$. The precision of $\mathrm{BMD}$ measurement at the lumbar spine is affected by high BMI, presumably by abdominal fat $[25,26]$. Finally, the decreased BMD of dieting women may be an artifact following an increase in bone area determined by DXA scanners $[27,28]$.

Several qualitative ultrasound (QUS) studies reported that soft tissue slows the speed of sound (SOS) transmitted across bones, both clinical- [29-31], and in vivo situations $[32,33]$. On the contrary, SOS measured in vivo along bone is corrected for soft tissue thickness [34], and is only slightly affected by BMI [35].

This study, therefore, evaluates the hypothesis that comparing BMD and SOS propagation along bones in overweight and lean women may determine the role of overweight in BMD measured by DXA.

\section{Methods \\ Patients}

Subjects were recruited from women approaching the Endocrine Institute of the "Assaf Harofeh" Medical Center for measurement of BMD by DXA. Thirty-three consecutive postmenopausal women (median age 59 years, range 45-78) were included in the study. Participants were categorized to the Overweight group, $\mathrm{n}=22 ; \mathrm{BMI} \geq 27 \mathrm{~kg} /$ $\mathrm{m}^{2}$, or the Lean group, $\mathrm{n}=11 ; \mathrm{BMI} \leq 21 \mathrm{gm} / \mathrm{m}^{2}$. Candidates were excluded from the study if they had BMI $>21$, $<27$, a metabolic bone disease such as hyper- or hypoparathyroidism, premature menopause (before the age of 40), Paget's disease, osteomalacia, osteogenesis imperfecta, or renal osteodystrophy. Women with debilitating diseases such as severe cardio-pulmonary, chronic liver, collagen vascular, or malignant diseases were also excluded from the study. Previous treatment with boneaffecting medications such as bisphosphonates, calcitonin, fluoride, anabolic steroids, glucocorticoids, anticonvulsants, thiazide, or higher-than-recommended doses of vitamin A and D precluded enrolment in the study. Medical history and life style characteristics were retrieved from dedicated case record forms.

\section{Bone measurements}

SOS measurements using Sunlight Omnisense ${ }^{\mathrm{TM}}$ (Sunlight Medical Ltd., Tel Aviv, Israel) were performed along the distal third of the radius of the non-dominant limb
(RAD), proximal phalanx of the index finger (PLX), and the mid-shaft tibia (TIB), using an acoustic gel. Data were reported as SOS, and T- and Z-scores as compared to the device's female Caucasian Reference Database [36]. SOS measurement by this device discriminates women with hip [37], vertebral [38] and forearm fractures from postmenopausal control. BMD of the lumbar spine $\left(\mathrm{L}_{2}-\mathrm{L}_{4}\right)$ and femoral neck was obtained by DXA (Hologic QDR 4500 Elite $^{\circledast}$ ). The relevant T- and Z-scores were derived from the manufacturer's database.

\section{Laboratory tests}

Blood samples were collected by venicpuncture for determination of serum bone specific alkaline phosphatase (BSAP) activity (ALKPHASE-B, Meta-Biosystems Inc, Mountain View, CA) with sensitivity of $0.7 \mathrm{U} / \mathrm{L}$, intra- and inter assay CV of 5.2 and 5.8\%, respectively. Normal reference values for females are 14.2-42.7 U/L. Deoxypyridinoline (DPD) excretion was determined in the first morning post-void specimen (Pyrilinks-D, Meta-Biosystems Inc, Mountain View, CA). Normal DPD reference values are: $3.0-7.4 \mathrm{~nm} / \mathrm{mm}$ of creatinine. The sensitivity of the assay is $1.1 \mathrm{~nm} / \mathrm{mm}$, intra- and inter assay CV are 4.8 and $8.4 \%$, respectively.

\section{Ethical considerations}

Every participant signed an informed consent. The institutional and governmental ethical committees approved this study.

\section{Statistical methods}

Descriptive statistics, Mann-Whitney U test, and Spearman rank order correlation were employed when appropriate. The non-parametric tests were used for analysis because of small numbers that did not assume a Gausian distribution. A $P$ value lower than 0.05 was considered statistically significant throughout the study.

\section{Results}

As pre-selected, the Overweight group had a higher mean BMI as compared with the Lean group $(30.9 \pm 2.7,19.6 \pm$ 1.2 , respectively, $P<0.0001)$. Both groups were of comparable age and were beyond the early postmenopausal stage (Table 1). All patients seldom participated in physical activity and consumed moderate amounts of calcium daily.

Mean $\mathrm{BMC}$, bone mineral area and the derived $\mathrm{BMD}$ of the lumbar spine were similar in both study groups. However, the corresponding $\mathrm{BMC}$ and $\mathrm{BMD}$ of the femoral neck were higher in the Overweight group as compared with the Lean group (Table 2). Bone area of the femoral neck was similar in both study groups. Bone SOS at the RAD, PLX and TIB did not differ significantly in both groups of patients. In the Lean group, SOS Z score at the 
Table I: Patient characteristics.

\begin{tabular}{|c|c|c|}
\hline & Overweight $(n=22)$ & Lean $(n=I I)$ \\
\hline Age (year) & $59.1 \pm 9.4^{*}$ & $58.5 \pm 7.8$ \\
\hline $\mathrm{BM} / \mathrm{a}\left(\mathrm{kg} / \mathrm{m}^{2}\right)$ & $30.9 \pm 2.7$ & $19.6 \pm 1.2^{* *}$ \\
\hline Years since menopause & $11.3 \pm 9.9$ & $8.0 \pm 6.6$ \\
\hline Physical activity (times/week) & $1.1 \pm 2.3$ & $1.8 \pm 2.9$ \\
\hline Calcium intake (mg/day) & $700 \pm 230$ & $725 \pm 167$ \\
\hline
\end{tabular}

$*$ Mean $\pm \mathrm{SD}, * * P<0.000 \mathrm{I}, \mathrm{aBMI}=$ Body mass index.

Table 2: Bone properties of the study groups (mean \pm SD).

\begin{tabular}{lcc}
\hline & Overweight $(\mathrm{n}=22)$ & Lean $(\mathrm{n}=\mathrm{II})$ \\
\hline Lumbar spine & & $35.83 \pm 5.22$ \\
$\quad$ Bone mineral content $(\mathrm{gr})$ & $37.27 \pm 7.09$ & $42.94 \pm 3.70$ \\
$\quad$ Bone area $\left(\mathrm{cm}^{2}\right)$ & $40.72 \pm 4.53$ & $-0.63 \pm 1.27$ \\
$\quad$ Bone mineral density (Z score) & $-0.17 \pm 1.11$ & $2.92 \pm 0.37^{*}$ \\
Femoral neck & $3.72 \pm 0.71$ & $4.75 \pm 0.35$ \\
$\quad$ Bone mineral content (gr) & $4.72 \pm 0.71$ & $-0.99 \pm 0.52^{* *}$ \\
$\quad$ Bone area (cm $\left.{ }^{2}\right)$ & $0.70 \pm 0.82$ & $0.70 \pm 1.20$ \\
$\quad$ Bone mineral density (Z score) & & \\
RAD & $0.24 \pm 1.29$ & $-0.70 \pm 1.36$ \\
SOS (Z score) & $-0.07 \pm 1.65$ & $0.31 \pm 1.48$ \\
$\quad$ PLX & & \\
SOS (Z score) & $-0.45 \pm 1.50$ & \\
TIB SOS (Z score) & & \\
\hline
\end{tabular}

$* P<0.005,{ }^{* * P}<0.0001, \mathrm{RAD}=$ radius. $\mathrm{PLX}=$ phalanx, $\mathrm{TIB}=$ tibia, $\mathrm{SOS}=$ speed of sound

RAD was higher than the age-adjusted BMD of the femoral neck $(P<0.01)$ and the lumbar spine $(P<0.05)$. The SOS Z-score at the TIB was higher than the femoral neck BMD Z-score of the femoral neck in the Lean group $(\mathrm{P}<$ $0.05)$, but lower in the Overweight group $(\mathrm{P}<0.005)$. Whereas BMD of the femoral neck was highly correlated with BMI, SOS was unrelated to BMI at any measurement site (Fig. 1). In the Overweight group, SOS at the PLX positively correlated with BMD of the lumbar spine (Table 3 ), but not at the other two SOS measurement sites. In contrast, in the Lean group, SOS at the RAD and PLX positively correlated with BMD at both femoral neck and lumbar spine. It is worthwhile noting that in few cases SOS measurements at some sites are impossible (Table 3)

Urinary DPD excretion rates were similar in the Overweight and Lean groups of women $(6.2 \pm 3.4$ and $5.1 \pm$ 4.2, respectively, NS). Similarly, circulating BSAP was comparable in the study groups $(28.8 \pm 11.7$ and $19.7 \pm$ 8.8, respectively, NS). Neither DPD nor BSAP correlated with SOS or BMD in both groups of patients.

\section{Discussion}

This cross-sectional study reveals a high positive correlation between BMD at the femoral neck and BMI in postmenopausal women. In contrast, SOS propagated along bone is independent of BMI. SOS correlated with BMD in lean individuals, and to a lesser degree in overweight women. These findings suggest that the increased BMD commonly reported in overweight women may result from soft tissue interference with BMD determination by DXA. Our data of femoral neck BMD dependency on BMI is consistent with previous cross-sectional studies of postmenopausal women evaluating lumbar spine [3], femoral neck [40], combined lumbar spine and total femur $[9,10]$, and whole body BMD [40].

High BMI decreases the precision of BMD measurements in the setting $[25,26]$. In addition, In situ studies indicate a significant contribution of soft tissue to BMD accuracy measurement error [22,23]. Moreover, changes in BMD in weight-losing premenopausal women were judged artifactual due to opposite fluctuations in bone mineral concentration and bone area [28]. Therefore the association 

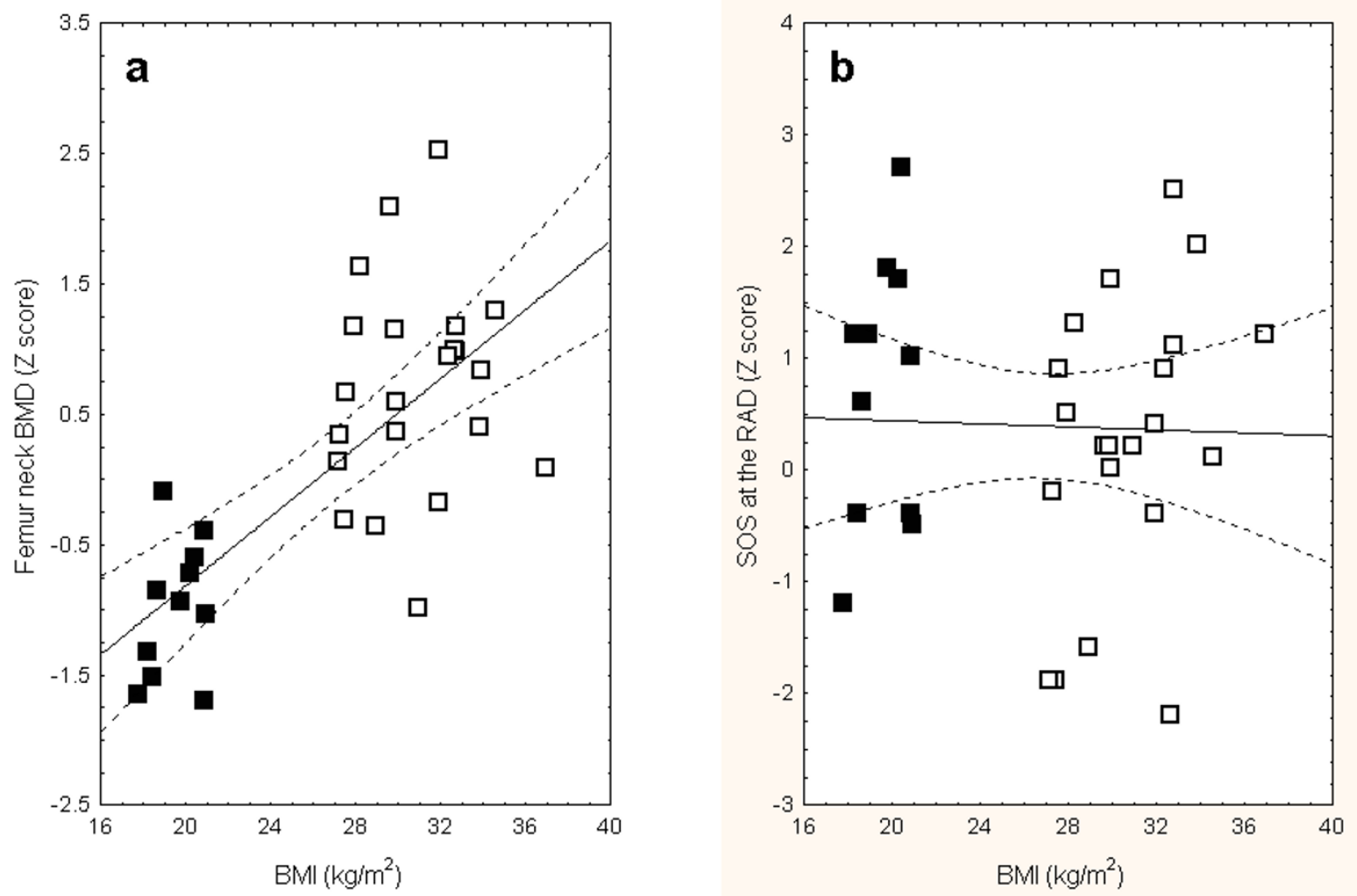

\section{Figure I}

Spearman rank order correlation coefficient of body mass index (BMI) and bone mineral density (BMD) at the femoral neck (a) and speed of sound (SOS) at the radius (b). Lean patient marked as filled squares and overweight women in open squares. The correlation between BMI and femoral neck BMD is statistically significant $(R=0.68, P<0.000 \mathrm{I})$.

between higher BMD and BMI is as yet uncertain [18-21]. Several investigators suggested that decreasing lumbar spine $[8,41,42]$, total body $[7,8]$ or femoral neck BMD [43] in dieting postmenopausal women indicate the role of soft tissue in interfering with bone densitometry by DXA. However, as weight loss is associated with increased bone turnover $[7,8]$ and secondary hyperparathyroidism that is preventable by calcium supplementation [44]. We believe that this $\mathrm{BMD}$ decline results from genuine changes in the bone and not from a lower interfering effect of soft tissue. Our data of higher femoral neck BMD in the Overweight group, similar SOS in the two groups that is soft tissue independent, and is only slightly affected by BMI (34), and a correlation between SOS and BMD only in the Lean group suggest that the increased BMD in the Overweight group is spurious in accordance with the previous suggestion [28]. In contrast to our data, two recent prospective studies $[9,10]$ of placebo arms of anti- resorption treatments indicated accelerated bone loss and higher bone turnover [10] in thin women. However, in contrast to our cohort of patients, these studies evaluated early postmenopausal women. At this early stage of changes following menopause, the impact of thinness on bone resorption may be higher.

QUS is dependent on both BMD and bone micro architecture. This may explain the fact that some reported low correlation between QUS and BMD $[45,46]$ while others found high site matched correlations between QUS and BMD $[47,48]$. Therefore, the meaning of varying Z-scores of BMD $Z$ and SOS in the Lean group and to lesser degree in the Overweight group is uncertain. Our data of similar SOS in both the Overweight and Lean groups is in accordance with a previous study of excised bone [33] and a clinical [34], and is only slightly affected by BMI revealing a 
Table 3: Spearman rank order correlation between bone mineral density and speed of sound at various measurement sites.

\begin{tabular}{|c|c|c|c|c|c|c|}
\hline \multirow[t]{2}{*}{ Pair of variables } & \multicolumn{3}{|c|}{ Overweight } & \multicolumn{3}{|c|}{ Lean } \\
\hline & $\mathrm{n}$ & $\mathrm{R}$ & $P$ value & $\mathrm{n}$ & $\mathrm{R}$ & $P$ value \\
\hline RAD \& Femoral neck & 21 & 0.15 & NS & 11 & 0.57 & $<0.05$ \\
\hline RAD \& Lumbar spine & 21 & 0.32 & NS & 11 & 0.53 & $<0.05$ \\
\hline TIB \& Femoral neck & 22 & 0.31 & NS & 9 & 0.07 & NS \\
\hline TIB \& Lumbar spine & 22 & 0.40 & NS & 9 & -0.23 & NS \\
\hline PLX \& Femoral neck & 18 & 0.35 & NS & 11 & 0.39 & $<0.05$ \\
\hline PLX \& Lumbar spine & 18 & 0.58 & $<0.05$ & 11 & 0.77 & $<0.001$ \\
\hline
\end{tabular}

$R A D=$ radius, $T I B=$ tibia, $P L X=$ phalan $x$

lack of correlation between BMI percentiles and SOS using the same QUS system.

QUS systems that measure SOS across the bone are affected by the soft tissue size [29-31]. In contrast, Omnisense detects the first signal to arrive at the receiving transducer, according to Snell's Law, and the principle of Minimal Action. The time taken by the signal to travel between the transmitter and the receiver is the parameter measured by Omnisense The system's software uses a proprietary algorithm to analyze the various SOS variables and calculates the patient's bone SOS, and eliminating the effect of soft tissue surrounding the bone.

The apparent limitations of this study are the small number of enrolled patients that may account in part to lack of correlation. Indeed in a study of 290 subjects significant negative correlation were found between SOS at the radius and tibia and BMI and \% total body fat [49]. Additional limitation of our study arethe use of a crosssectional as compared to a prospective design, and the lack of data on total and regional body fat in relation to BMD and SOS. As the bone sites measured by DXA vs. SOS are completely different, one should be cautious in drawing any conclusions of their relationship to BMI. The higher SD of BMI in the overweight group means higher probability for positive correlations. It may not be appropriate to compare significances of correlations between BMI and bone parameters. BSAP was 50\% higher in overweight vs. lean, but because of large inter-individual variation this difference did not reach significance. Therefore, the conclusion that the levels were similar may not be valid.

\section{Conclusions}

The comparison of BMD and SOS in groups of overweight and lean post-menopausal women indicates that the high BMD associated with overweight results from soft tissue interference with DXA.

\section{Competing interests}

None declared.

\section{Authors' contributions}

MS participated in the study design and data collection. PG participated in study design and data analysis. MJR participated in study design and critical review of the manuscript. MW participated in study design and wrote the manuscript.

\section{References}

I. Kelly TL, Slovik DM, Schoenfeld DA and Neer RM: Quantitative digital radiography versus dual photon absorptiometry of the lumbar spine J Clin Endocrinol Metab 1988, 67:839-844.

2. Wahner HW, Dunn WL, Brown ML, Morin RL and Riggs BL: Comparison of dual-energy $X$-ray absorptiometry for bone mineral measurements of the lumbar spine Mayo Clin Proc 1988, 63:1075-1084.

3. Douchi T, Yamamoto S, Oki T, Maruta K, Kuwahata R, Yamasaki H and Nagata $Y$ : Difference in the effect of adiposity on bone density between pre- and postmenopausal women Maturitas 2000 , 34:26I-266.

4. Andersen RE, Wadden TA and Herzog RJ: Changes in bone mineral content in obese dieting women Metabolism 1997, 46:857861 .

5. Fogelholm GM, Sievänen HT, Kukkonen-Harjula TK and Pasanen ME: Body mineral density during reduction, maintenance and regain of body weight in premenopausal, obese women Osteoporos Int 2001, I 2:199-206.

6. Shapses SA, Von Thun NL, Heymsfield SB, Ricci TA, Ospina M, Pierson JR and Stahl T: Bone turnover and density in obese premenopausal women during moderate weight loss and calcium supplementation / Bone Miner Res 200 I, I 6: I 329-1 336.

7. Ricci TA, Heymsfield SB, Pierson RN Jr, Stahl T, Chowdhury HA and Shapses SA: Moderate energy restriction increases bone resorption in obese postmenopausal women $\mathrm{Am} J \mathrm{Clin}$ Nutr 2001, 73:347-352.

8. Chao D, Espeland MA, Farmer D, Register TC, Lenchik L, Appelgate WB and Ettinger WH Jr: Effect of voluntary weight loss on bone mineral density in older overweight women J Am Geriatr Soc 2000, 48:753-759.

9. Ravn P, Cizza G, Bjarnason NH, Thompson D, Daley M, Wasnich RD, McClung M, Hoskins D, Yates AJ and Christiansen C: Low body mass index in early postmenopausal women. Early Postmenopausal Intervention Cohort (EPIC) study group J Bone Miner Res 1999, I 4:1622-1627.

10. Bjarnason $\mathrm{NH}$ and Christiansen $\mathrm{C}$ : The influence of thinness and smoking on bone loss and response to hormone replacement therapy in early postmenopausal women / Clin Endocrinol Metab 2000, 85:590-596. 
II. Van der Voort DJM, Brandon S, Dinant GJ and van Wersch JWJ: Screening for osteoporosis using easily obtainable biomedical data: diagnostic accuracy of measured, self-reported and recalled $B M I$, and related costs of bone mineral density measurements Osteoporos Int 2000, I I:233-239.

12. Van der Voort DJM, Geusens PP and Dinant GJ: Risk factors for osteoporosis related to their outcome: fractures Osteoporos Int 2001, I 2:630-638.

13. Eddy DM, Johnson CC Jr, Cummings SR, Dawson-Hughes B, Lindsay R, Melton JL III and Slemenda CW: Osteoporosis: review of the evidence for prevention, diagnosis, and treatment and costeffectiveness analysis Osteoporos Int 1998, 8 Suppl 4: |-88.

14. National Osteoporosis Foundation: Osteoporosis. Physician's guide to prevention and treatment of osteoporosis National Osteoporosis Foundation, Washington DC 1998.

15. Black DM, Steinbuch M, Palermo L, Dargent-Molina P, Lindsay R, Hoseyni $M S$ and Johnell $O$ : An assessment tool for predicting fracture risk in postmenopausal women Osteoporos Int 2001, 1 5:519-528.

16. Slemenda CW: Body composition and skeletal density: Mechanical loading or something more? J Clin Endocrinol Metab 1995, 80:I76I-I763.

17. Liel Y, Edwards J, Shary J, Spicer KM, Gordon L and Bell NH: The effects of race and body habitus on bone mineral density of the radius, hip, and spine in postmenopausal women $J$ Clin Endocrinol Metab 1988, 66: I247-1250.

18. Bolotin $\mathrm{HH}$ : A new perspective on the causal influence of soft tissue composition on DXA-measured in vivo bone mineral density J Bone Miner Res 1998, I 3: I739-I746.

19. Bolotin $\mathrm{HH}$ : Inaccuracies inherent in dual-energy X-ray absorptiometry in vivo bone mineral densitometry may flaw osteopenic/osteoporotic interpretations and mislead assessment of antiresorptive effectiveness Bone 200I, 28:548-555.

20. Tothill $P$ and Avenell $A$ : Errors in dual-energy $X$-ray absorptiometry of the lumbar spine owing to fat distribution and soft tissue thickness during weight change $B r$ J Radiology 1994, 67:7 I75.

21. Tothill P and Hannan WJ: Comparisons between Hologic QDR I 000W, QDR 4500A, and Lunar Expert dual-energy X-ray absorptiometry scanners used for measuring total body bone and soft tissue Ann NY Acad Sci 2000, 904:63-7I.

22. Svendsen OL, Hassager C, Skodt V and Christiansen C: Impact of soft tissue on in vivo accuracy of bone mineral measurements in the spine, hip, and forearm: a human cadaver study J Bone Miner Res 1995, 10:868-873.

23. Lochmüller E-M, Krefting N, Bürklein D and Eckstein F: Effect of fixation, soft-tissues, and scan projection on bone mineral measurements with dual energy $X$-ray absorptiometry (DXA) Calcif Tissue Int 2001, 68: I40-145.

24. Madsen OR, Jensen JE and Sorensen $\mathrm{OH}$ : Validation of a dual energy X-ray absorptiometer: measurement of bone mass and soft tissue composition Eur J Appl Physiol Occup Physiol 1997, 75:554-558

25. Patel R, Seah M, Blake GM, Jefferies AL, Crane FM and Fogelman I: Concordance and precision of dual $X$-ray absorptiometry with a 10 s scan $\mathrm{Br} J$ Radiology 1996, 69:816-820.

26. Patel R, Blake GM, Rymer J and Fogelman I: Long-term precision of DXA scanning assessed over seven years in forty postmenopausal women Osteoporos Int 2000, I I :68-75.

27. Prentice A, Parsons TJ and Cole TJ: Uncritical use of bone mineral density in absorptiometry may lead to size-related artifacts in the identification of bone mineral determinants $\mathrm{Am} J$ Clin Nutr 1994, 60:837-840.

28. Van Loan MD, Johnson HL and Barbieri TF: Effect of weight loss on bone mineral content and bone mineral density in obese women Am J Clin Nutr 1998, 67:734-738.

29. Rico H, Gomez M, Aguado F, Villa LF, Hernandez ER and Cortes ]: Impact of weight in obese subjects on bone speed of sound Invest Radiol 1999, 34:596-599.

30. Chappard C, Camus E, Lefebvre F, Guillot G, Bittoun J, Berger G and Laugier P: Evaluation of error bounds on calcaneal speed of sound caused by surrounding soft tissue J Clin Densitom 2000, 3:|2|-|3|.

31. Gregg EW, Kriska AM, Salamone LM, Wolf RL, Roberts MM, Ferrell RE, Anderson SJ, Kuller LH and Cauley JA: Correlates of quantita- tive ultrasound in the Women's Healthy Lifestyle Project Osteoporos Int 1999, 10:416-424.

32. Kotzki PO, Buyck D, Hans D, Thomas E, Bonnel E, Favier F, Meunier PJ and Rossi M: Influence of fat on ultrasound measurements of the os calcis Calcif Tissue Int 1994, 54:91-95.

33. Hausler KD, Rich PA and Barry EB: Water bath and contact methods in ultrasonic evaluation of bone Calcif Tissue Int 1997, 6I:26-29.

34. Pearce S, Hurtig MB, Runciman J and Dickey J: Effect of age, anatomic site and soft tissue on quantitative ultrasound $J$ Bone Miner Res 2000, I5 SuppI I:S407.

35. Eliakim A, Nemet D and Wolach B: Quantitative ultrasound measurements of bone strength in obese children and adolescent J Pediatr Endocrinol Metab 200I, 14:159-164.

36. Weiss M, Ben-Shlomo AB, Hagag $P$ and Rapoport M: Reference database for bone speed of sound by a novel quantitative multi-site device Osteoporos Int 2000, I I:688-696.

37. Weiss M, Ben-Shlomo A, Hagag P and Ish-Shalom S: Discrimination of hip fracture by quantitative ultrasound measurement at the radius Osteoporos Int 2000, I I:4 I I-4I6.

38. Knapp KM, Blake GM, Spector TD and Fogelman I: Multisite quantitative ultrasound: precision, age- and menopause-related changes, fracture discrimination, and $T$-score equivalence with dual-energy X-ray absorptiometry Osteoporos Int 200I, I 2:456-464.

39. Knapp KM, Blake GM, Fogelman I, Doyle DV and Spector TD: Multisite quantitative ultrasound: Colles' fracture discrimination in postmenopausal women Osteoporos Int 2002, 13:474-479.

40. Taaffe DR, Cauley JA, Danielson M, Nevitt MC, Lang TF, Bauer DC and Harris TB: Race and sex effects on the association between muscle strength, soft tissue, and bone mineral density in healthy elders: the Health, Aging, and Body Composition Study J bone Miner Res 200I, 16: I 343-I 352 .

4I. Avenell A, Richmond PR, Lean ME and Reid DM: Bone loss associated with a high fibre reduction diet in postmenopausal women Eur J Clin Nutr 1994, 48:56I-566.

42. Bano G, Rodin DA, Pazianas M and Nussey SS: Reduced bone mineral density after surgical treatment for obesity Int J Obes Relat Metab Disord 1999, 23:361-365.

43. Gossain VV, Rao DS, Carella MJ, Divine G and Rovner DR: Bone mineral density (BMD) in obesity effect of weight loss J Med 1999, 30:367-376.

44. Jensen LB, Kollerup G, Quaade F and Sorensen OH: Bone mineral changes in obese women during a moderate weight loss with and without calcium supplementation J Bone Mine Res 200I, 16:14I-I47.

45. He YQ, Fan B, Hans D, Li J, Wu CY, Njeh CF, Zhao S, Lu Y, TsudaFutami $E$ and Fuerst $T$ et al.: Assessment of a new quantitative ultrasound calcaneus measurement: precision and discrimination of hip fracture in elderly women compared with dual X-ray absorptiometry Osteoporos Int 2000, I I :354-360.

46. Cheng XG, Nicholson PHF, Boonen S, Lowet G, Brys P, Aerssens J, Van der Perre G and Dequerker J: Prediction of vertebral strength in vitro by spinal bone densitometry and calcaneal ultrsound J Bone Miner Res 1997, I 2:172I-I728.

47. Laugier P, Droin P, Laval-leantet AM and Berger G: In vitro assessment of the relationship between acoustic properties and bone mass density of the calcaneus by comparison of ultrasound parametric imaging and quantitative computed tomography Bone 1997, 20:157-165.

48. Chappard C, Laugier P, Fournier B, Roux C and Berger G: Assessment of the relationship between broadband ultrasound attenuation and bone mineral density at the calcaneus using BUA and DXA Osteoporos Int 1997, 7:316-322.

49. Knapp K: An Evaluation of Quantitative Ultrasound measurements at Multiple Sites for Clinical and Genetic Studies of Osteoporosis PhD thesis, University of London 2000.

\section{Pre-publication history}

The pre-publication history for this paper can be accessed here:

http://www.biomedcentral.com/1471-2474/4/15/prepub 